Науковий вісник НлТУ України Scientific Bulletin of UNFU http://nv.nltu.edu.ua

https://doi.org/10.15421/40281123

Article received 10.12.2018 p.

Article accepted 27.12.2018 p.

удк 004.896:539.431
ISSN 1994-7836 (print)

ISSN 2519-2477 (online)

$@ \bowtie$ Correspondence author

O. O. Vodka

oleksii.vodka@gmail.com

С. В. Погребняк, О. О. Водка

Національний технічний університет "Харківський політехнічний інститут", м. Харків, Украӥна

\title{
МОДЕЛЮВАННЯ МЕХАНІЧНОЇ ПОВЕДІНКИ ЕЛАСТОМІРНИХ МАТЕРІАЛІВ ЗА ДОПОМОГОЮ ШТУЧНОЇ НЕЙРОННОЇ МЕРЕЖІ
}

У XXI ст. нейронні мережі широко використовують у різних сферах, зокрема в комп'ютерному моделюванні та механіці. Така популярність через те, що вони дають високу точність, швидко працюють та мають дуже широкий спектр налаштувань. Створено програмний продукт із використанням елементів штучного інтелекту для інтерполяції та апроксимації експериментальних даних. Програмне забезпечення повинно коректно працювати та давати результати з мінімальною похибкою. Інструментом розв'язання задачі було використання елементів штучного інтелекту, а точніше - нейронних мереж прямого поширення. Збудовано нейронну мережу прямого поширення. Ї̈̈ навчив вчитель із використанням методу зворотного розповсюдження похибки на основі навчаючої вибірки попередньо проведеного експерименту. Для тестування було побудовано декілька мереж різної структури, що отримували на вхід однаковий набір даних, якого не використовували під час навчання, але він був відомий з експерименту. Отже, було знайдено похибку мережі за кількістю виділеної енергії та середньоквадратичним відхиленням. Докладно описано тип мережі та іiі топологію. Метод навчання і підготовки навчаючої вибірки також описано математично. Внаслідок проведеної роботи збудовано та протестовано програмне забезпечення 3 використанням штучної нейронної мережі та визначено її похибку.

Ключові слова: штучна нейрона мережа; комп'ютерне моделювання; штучний інтелект; апроксимація; інтерполяція; програмне забезпечення.

Вступ. Сучасні матеріали мають досить складну внутрішню структуру. Це визначає їх механічну поведінку. Еластомери - це одна з багатьох груп матеріалів, що мають не звичайну структуру та складну механічну поведінку. Еластомірні матеріали мають певні особливості: витримують дуже великі деформації (понад 100 \%), мають відмінності у формі кривої деформування при різних рівнях деформації та різні траєкторії завантаження/розвантаження. Сьогодні створено значну кількість моделей для опису деформаційної кривої таких матеріалів. Ці моделі враховують деякі аспекти кривої деформації. Серед найпопулярніших є модель Муні-Рівліна (Mooney, 1940; Rivlin, 1948), Неогуківська модель (Ogden, 1997), Арруда-Бойса (Arruda \& Mary, 1993), Бергстрем-Бойса (Bergström \& Boyce, 1998) та ін.

Одним із найпопулярніших альтернативних методів побудови кривої деформації $є$ використання штучних нейронних мереж (ШНМ) (Pidaparti \& Palakal, 1993; Necat \& Rasit, 2006). За правильного вибору параметрів мережі, можна досягти гарних результатів не лише в наближенні даних, але й в інтерполяції (Furukawa \& Hoffman, 2004, 2007). Більшість робіт із застосуванням ШНМ до наближення кривої деформації спрямовані на різні матеріали. Наприклад, у (Pidaparti \& Palakal, 1993) розроблено ШНМ. Отримують на вході такі параметри: кут волокна, дельта-стрес, напруження, кутовий цикл завантаження/вивантаження (Elnashai \& Ambraseys,
2007; Sumantra et al., 2009). На виході ця мережа дає значення деформацій (Zhang, Klein \& Friedrich, 2002; McBride, Malinov \& Sha, 2004).

У роботі (Furukawa \& Hoffman, 2004) для пошуку кривої деформацій-напружень використовують мережу прямих поширення. На вхідні дані застосовують три напруги (1 поточна і 2 попередні) та 3 напруги (1 поточна і 2 попередні). Поточне напруження - це відповідь ШНМ. Переваги цієї ШНМ є в комбінації еластичних та пластикових моделей і хороше узгодження 3 експериментальними даними (Bahrami, Mousavi \& Ekrami, 2005; Zhou et al., 2009).

У статті (Furukawa \& Hoffman, 2007) було використано мережу прямого розповсюдження для сталевих колійних стовпчиків, на вхід яких буо застосовано такі параметри: напруження та деформація (4 напруження, три 3 них були попередні та три попередні деформації). На виході отримано поточні деформації (Sterjovski et al., 2005; Zhang \& Friedrich, 2003). Внаслідок експериментів було отримано те, що мережа дає досить гарний результат за добре навченої мережі (Malinov, Sha \& McKeown, 2001; Okuyucu \& Arcaklioglu, 2007). Така мережа дає змогу в майбутньому інтерполювати проміжні результати з високою точністю і легко отримувати кількість випромінюваної енергії. Тобто ця робота поєднує можливості двох попередніх (Furukawa \& Hoffman, 2007; McBride, Malinov \& Sha, 2004).

\section{Інформація про авторів:}

Погребняк Сергій Віталійович, студент, кафедра динаміки та міцності машин. Email: pogrebnyak.vetal@mail.ru

Водка Олексій Олександрович, канд. техн. наук, доцент, кафедра динаміки та міцності машин. Email: oleksii.vodka@gmail.com

Цитування за Дсту: Погребняк С. В., Водка О. О. Моделювання механічної поведінки еластомірних матеріалів за допомогою штучної нейронної мережі. Науковий вісник НлтУ України. 2018, т. 28, № 11. С. 130-134.

Citation APA: Pogrebnyak, S. V., \& Vodka, O. O. (2018). Modeling of mechanical behavior of elastomeric materials using an artificial neural network. Scientific Bulletin of UNFU, 28(11), 130-134. https://doi.org/10.15421/40281123 
Часто нейронні мережі використовують для прогнозування властивостей матеріалів (зокрема композитних) із набору даних. ШНМ виконує хороший прогноз у цій сфері, що підтверджують великою кількістю робіт у цьому напрямі (Elnashai \& Ambraseys, 2007; Sumantra et al., 2009). Незважаючи на значну різноманітність використання нейронних мереж під час наближення кривих деформування, недостатню увагу приділяють моделюванню гумоподібних матеріалів. Також у цих роботах практично немає аналізу на вибір раціональної структури мережі та вибору вхідних параметрів.

Викладення основного матеріалу. У роботі запропоновано розробити програмний комплекс, що дає змогу автоматизувати обробку експериментальних даних із використанням штучних нейронних мереж. Для цього необхідно виконати такі завдання:

- з літературних оглядів визначити типові способи побудови штучної нейронної мережі (ШНМ) та результати їхньої роботи;

- розробити ШНМ для апроксимації та інтерполяції експериментальних даних за допомогою бібліотеки pyBrain та мови програмування Python;

- підготувати дані для навчання та провести його;

- протестувати роботу програмного комплексу та оцінити точність її роботи.

Штучні нейронні мережі (ШНМ) мають такий загальний вигляд:

$$
y=f\left(\sum_{i=1}^{n} w_{i} x_{i}\right),
$$

де: $n$ - кількість вхідних параметрів, $w_{i}$ - вагові коефіцієнти, $x_{i}$ - вхідні сигнали, $f(\ldots)$ - функція активації. Насамперед вагові коефіцієнти задаються випадковим чином, тому для їхньої корекції проводять навчання.

Моделювання навчання за допомогою комп'ютера передбачає постійну зміну ваг і порогів так, що класифікація набуває вищого рівня після кожного кроку. Навчання може бути реалізовано різними алгоритмами:

• навчання з учителем - відомі вихідні результати нейронної мережі;

- навчання без учителя - нейронна мережа опрацьовує тільки вхідні дані та самостійно формує вихідні результати. Такі мережі називають самоорганізаційними;

- навчання з підкріпленням - система призначення штрафів і заохочень від середовища.

Метою навчання є зменшення похибки відповіді мережі (Zhang, Klein \& Friedrich, 2002). За кожного з типів навчання відбувається знаходження подібностей. Під час навчання 3 учителем відбувається корекція вагових коефіцієнтів, після кожної ітерації вчитель порівнює відповідь мережі та відповідь, яку повинні були отримати та корегує їх з метою зменшення різниці між відповіддю мережі та відповіддю експерименту (цю помилку називають помилкою навчання).

У роботі використовували навчання з вчителем методом зворотного розповсюдження помилки (Bergström \& Воусе, 1998). Алгоритм дії такий:

1) задаються початкові вагові коефіцієнти випадковим чином;

2) подається на вхід ШНМ наступний вектор із навчаючої вибірки;

3) обчислюється вихідне значення мережі;

4) обчислюється різниця між відповіддю мережі та потрібним значенням;

5) корегуються вагові коефіцієнти для зменшення похибки;
6) повторюються кроки 32 по 5 доти, поки не мінімізується похибка до заданої або до кількості ітерацій.

Корекція вагових коефіціснтів вихідного шару. Вводиться величина $\delta$, яка відповідає такій формулі:

$$
\delta_{q}=O U T_{q}\left(1-O U T_{q}\right)\left(T_{q}-O U T_{q}\right),
$$

де: $T_{q}$ - потрібне значення; OUT $T_{q}$ - відповідь мережі; індекс $p$ - нейрон, з якого виходить синоптична вага; $q$ - нейрон, у який входе.

Далі корегуємо вагові коефіцієнти

$$
w_{p-q}(i+1)=w_{p-q}(i)+\mu \delta_{q} O U T_{p},
$$

де: $i$ - номер поточної ітерації навчання; $w_{p-q}-$ вага синоптичного нейрону, що з'єднує нейрон $p$ з нейроном $q$; $\mu$ - коефіцієнт швидкості навчання; $O U T_{q}-$ вихід 3 нейрона $p$.

Корекція вагових коефіцієнтів прихованого шару:

$$
\delta_{q}=O U T_{q}\left(1-O U T_{q}\right) \sum_{k=1}^{N} \delta k w_{q-k} .
$$

Корекція вагових коефіцієнтів відбувається за формулою, аналогічною для корекції вихідного шару.

Отримання даних для навчання мережі. Дослідження статичної міцності і визначення кривої деформації проводили 3 використанням спеціалізованого вимірювального комплексу Цвік/Роелл Z100 (Necat \& Rasit, 2006; Larin, Petrova \& Mateichyk, 2013). Зразки відповідали геометричним стандартам для механічних випробувань гумових подібних матеріалів і гумокордних композитів ISO 527-2 1A.

Зразки мали такі геометричні параметри: фактичну товщину $\left(10^{ \pm 0,1} \mathrm{Mм}\right)$; ширина (10 мм); довжина робочої частини (80 мм); загальна довжина (150 мм). Товщина зразків має варіації $1 \%$ через технологічні допуски, який існує у виробництві композитних листів. Інші параметри мають точні значення, тому що всі зразки були отримані способом розрізання їх, використовуючи один і той же штамп зі стандартним розміром. На рис. 1 зображено схематичне креслення геометрії зразків та його фотографіï.

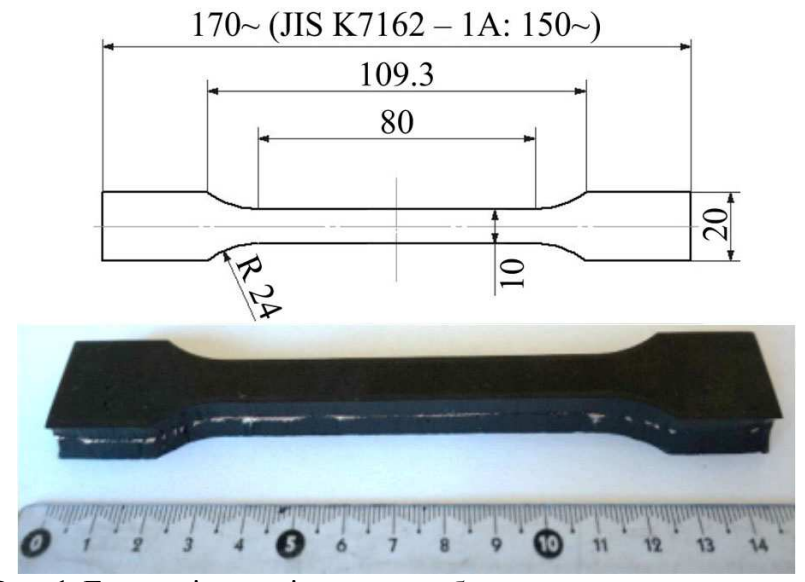

Рис. 1. Геометрія зразків для випробувань

Зразки були жорстко закріплені за допомогою механічних затискачів. Отже, виміряли зусилля, які відбуваються в нижніх затискачах за допомогою стандартних датчиків (максимальне зусилля $10 \mathrm{\kappa H}^{ \pm 0,01 \mathrm{~N}}$ ). Результати автоматично записуються кожні 0,1 секунди. Під час випробувань зразки мали циклічні навантаження з фіксованими рівнями деформації, що дає змогу визначати пружні властивості таких матеріалів у стабілізованому стані. Характерні криві деформації-напруження експе- 
рименту проводили за програмою навантаження (рис. 2). Напруження, отримані за цими програмними навантаженнями, наведено на рис. 2, $a$ та 2,б.
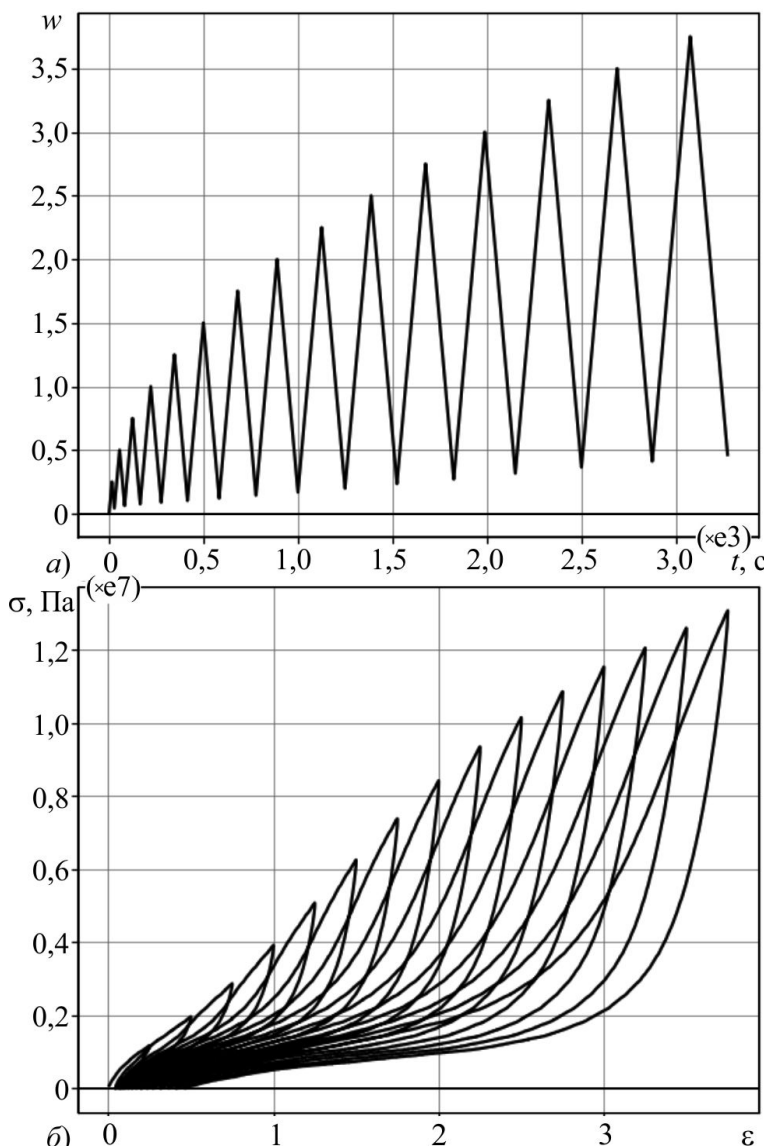

Pис. 2. Цикли навантаження, що використовувались для навчання мережі: $a$ - програма навантаження; $\sigma$ - результат експерименту

Після проведення цього експерименту було отримано файл із даними залежності часу, напруження та деформації. оскільки проводити цей експеримент- це коштовна річ, було вирішено розробити програмний комплекс, який відтворював результати. Цей спосіб є менш затратний фінансово та займає менше часу.

Із цього експерименту було обрано 2 цикли для навчання та 1 цикл для оцінювання похибки мережі (рис. 3). На цьому рисунку зображено дані для навчання та оцінювання похибки роботи нейронної мережі (номери 1 та 3 використовували для навчання, а для оцінювання похибки - дані під номером 2).

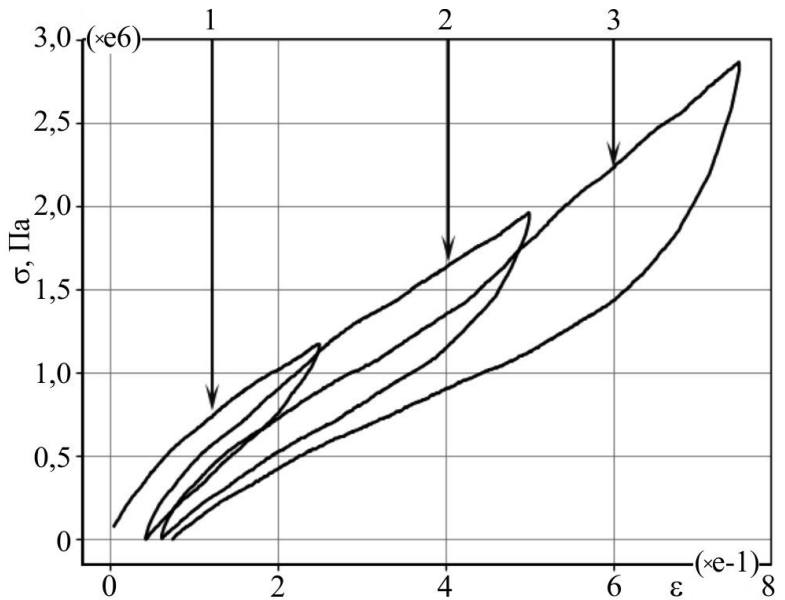

Рис. 3. Вхідні дані для навчання ШНМ
За площею петель можна визначити кількість теплоти, яка виділилась під час проведення експерименту, або за такою формулою

$$
W=\frac{1}{2 T} \int_{0}^{T} \sigma(t) \varepsilon(t) d t,
$$

де $T$ - час.

Визначене тепловиділення композитних матеріалів $\epsilon$ важливою практичною задачею під час досліджень теплового стану композитних матеріалів за циклічного навантаження.

Cтруктура мережі. Для побудови ПЗ використовували мережу прямого поширення, в якій всі дії відбуваються лише від початку до кінця. Передусім було зведено початкові дані в проміжок від -1 до 1. Таким кроком ми нормалізували початкові дані. Експериментальним способом було встановлено таку конфігурацію мережі (рис. 4), за якої вхідних нейронів 3 та вихідних 1. На вхід подаються: попередня деформація, тип деформації, максимальна деформація, яка була до поточного моменту. На виході мережа дає поточне напруження.

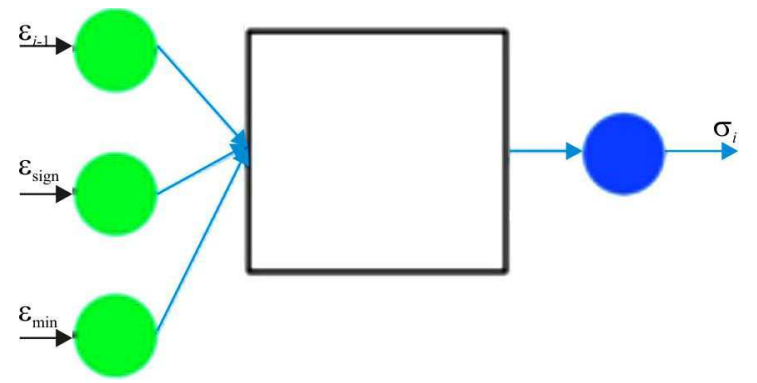

Рис. 4. Загальна схема мережі 1

Навчання мережі. Після нормалізації даних, всі набори даних додаються до навчаючої вибірки. Після чого починаємо тренувати їі з учителем. Отже, тренер, порівнюючи відповідь, яку дала ШНМ зі заданою, корегує в ту чи іншу сторону вагові коефіцієнти, добиваючись кращого результату мережі. У цьому варіанті використовували звичайний цикл, який запускав тренера на одну епоху навчання (один повний прохід по вибірці називають епохою навчання) і отримували квадратичну похибку. Отже, ми могли стежити за процесом навчання та за значенням квадратичної похибки, будувати графік залежності кількості ітерацій від похибки та слідкувати за швидкістю навчання, в ручному режимі задавати похибку або кількість ітерацій. Квадратична похибка - це половинна сума різниць між відповіддю мережі та тою, яку повинні були отримати у квадраті. Використаний тип навчання 3 тренером: метод зворотного розповсюдження похибки.

$$
H=\frac{1}{2} \sum_{x=1}^{n}\left(Z(x)-Z^{*}(x)\right)^{2},
$$

де: $Z^{*}(x)$ - результат $з$ експерименту; $Z(x)$ - відповідь мережі; $n$ - кількість елементів навчаючої вибірки.

Результати роботи ШНМ. Тестування мережі проводили на даних, які не використовували для навчання мережі. Оскільки мережу навчали на першій та третій петлі, а другу петлю не використовували, доцільно використати іiі для тестування навченої мережі. Отже, можна оцінити якість навчання та зрозуміти - перенавчена мережа чи ні. Результат тестування мережі зображено на рис. 5. 


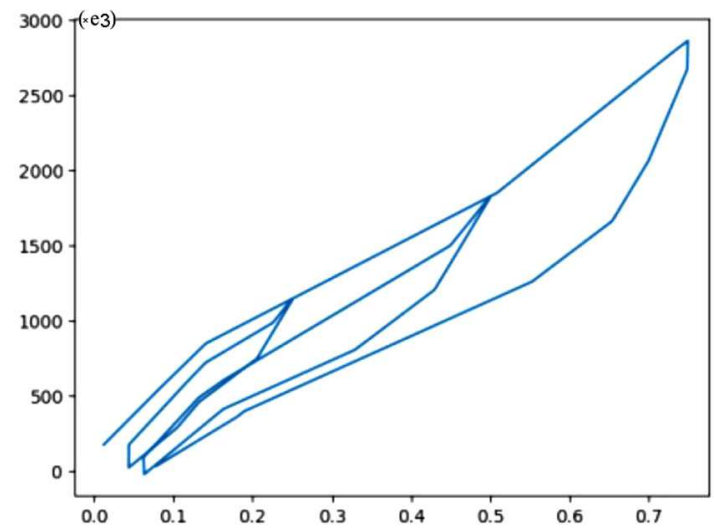

Рис. 5. Результат тестування мережі
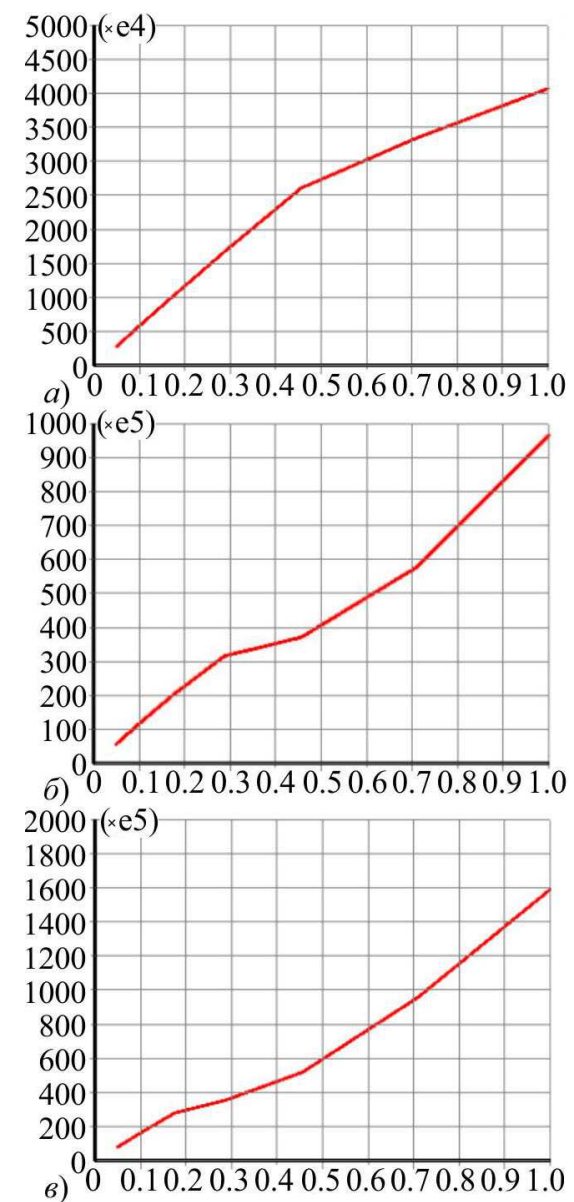

Рис. 6. Результати роботи мережі $з$ програмним комплексом ANSYS: $a$ ) перший; б) другий; в) третій крок навантаження

Далі ця мережа була інтегрована у програмний комплекс ANSYS. Для докладного розуміння принципу роботи ПК ANSYS та нейронної мережі було побудовано UML діаграму розгортання (рис. 7).

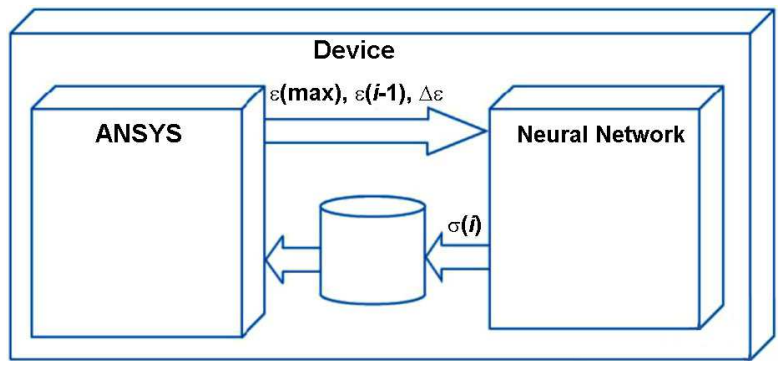

Рис. 7. UML діаграма розгортання

Програмний комплекс ANSYS запускає модуль нейронної мережі та передає вхідні параметри для неї. Далі модуль нейронної мережі нормалізує дані та подає їх на вхід нейронної мережі. Після отримання результату, модуль записує результат до файлу та завершує свою роботу. Після чого ПК ANSYS зчитує з файлу результат нейронної мережі та продовжує розрахунки (Larin, Petrova \& Mateichyk, 2013; Larin, Barkanov \& Petrova, 2016).

Висновки. У роботі побудовано штучну нейронну мережу, яка дає змогу апроксимувати та інтерполювати експериментальні дані. Отже, внаслідок роботи було:

- розроблено ШНМ апроксимуючу, проведено експеримент;

- 3 результату експерименту підготовлено дані, на основі яких було навчено модель;

- з результату експерименту підготовлено дані для тестування розроблених типів нейронних мереж;

- протестовано нейронну мережу та оцінено похибку за кількістю виділеної енергії та за середньоквадратичним відхиленням;

- інтегровано нейронна мережу в програмно розрахунковий комплекс ANSYS.

Вдячність. Цю роботу виконано за підтримки МОН України в рамках реалізації науково-дослідної роботи "Розробка методів математичного моделювання поведінки нових та композиційних матеріалів для оцінки ресурсу та прогнозування надійності елементів конструкцій" (№ ДР 0117U004969).

\section{Перелік використаних джерел}

Arruda, Ellen, M., \& Mary, C. Boyce. (1993). A three-dimensional constitutive model for the large stretch behavior of rubber elastic materials. Journal of the Mechanics and Physics of Solids, 41(2), 389-412. https://doi.org/10.1016/0022-5096(93)90013-6

Bahrami, A., Mousavi, Anijdan, S. H, \& Ekrami, A. (2005). Prediction of mechanical properties of DP steels using neural network model. Journal of alloys and compounds, 392(1-2), 177-182. https://doi.org/10.1016/j.jallcom.2004.09.014

Bergström, J. S., \& Boyce, M. C. (1998). Constitutive modeling of the large strain time-dependent behavior of elastomers. Journal of the Mechanics and Physics of Solids, 46(5), 931-954. https://doi.org/10.1016/S0022-5096(97)00075-6

Elnashai, A. S., \& Ambraseys, N. N. (2007). Development of Neural Network Based Hysteretic Models for Steel Beam-Column Connections Through Self-Learning Simulation.

Furukawa, T., \& Hoffman, M. (2004). Engineering Analysis with Boundary Elements. Journal of Earthquake Engineering, 28, 195204.

Furukawa, T., \& Hoffman, M. (2007). Engineering Analysis with Boundary Elements. Journal of Earthquake Engineering, 11, 453-467.

Larin, O., Barkanov, E., \& Petrova, I. (2016). Experimental observations of orthotropic elastic and viscoelastic characteristics of the elastomeric textile reinforced composites. Innovative solutions in repair of gas and oil pipelines, (pp. 192-203). Sofia: Bulgarian Society for destructive testing Publishers, $320 \mathrm{p}$.

Larin, O., Petrova, Yu., \& Mateichyk, V. (2013). Two-scale approach to modelling of pneumatic tyres, (pp. 123-128). Rzeszow: Politechnika Pzeszowska im. Ignacego Lukasiewicza, $260 \mathrm{p}$.

Malinov, S., Sha, W., \& McKeown, J. J. (2001). Modelling the correlation between processing parameters and properties in titanium alloys using artificial neural network. Computational materials science, 21(3), 375-394. https://doi.org/10.1016/S0927-0256(01)00160-4

McBride, J., Malinov, S., \& Sha, W. (2004). Modelling tensile properties of gamma-based titanium aluminides using artificial neural network. Materials Science and Engineering: A, 384(1-2), 129-137. https://doi.org/10.1016/j.msea.2004.05.072

Mooney, Melvin. (1940). A theory of large elastic deformation. Journal of applied physics, 11(9), 582-592.

Necat, Altinkok, \& Rasit, Koker. (2006). Modelling of the prediction of tensile and density properties in particle reinforced metal matrix composites by using neural networks. Materials \& design, 27(8), 625-631. https://doi.org/10.1016/j.matdes.2005.01.005 
Ogden, Raymond, W. (1997). Non-linear elastic deformations. Courier Corporation, $238 \mathrm{p}$.

Okuyucu, Hasan, Adem Kurt, \& Arcaklioglu, Erol. (2007). Artificial neural network application to the friction stir welding of aluminum plates. Materials \& design, 28(1), 78-84. https://doi.org/10.1016/j.matdes.2005.06.003

Pidaparti, R. M. V., \& Palakal, M. J. (1993). Material model for composites using neural networks. AIAA journal, 31(8), 1533-1535.

Rivlin, R. S. (1948). Large elastic deformations of isotropic materials IV. Further developments of the general theory. Phil. Trans. R. Soc. Lond. A. 241(835), 379-397. https://doi.org/10.1098/rsta.1948.0024

Sterjovski, Z., et al. (2005). Artificial neural networks for modelling the mechanical properties of steels in various applications. Journal of Materials Processing Technology, 170(3), 536-544. https://doi.org/10.1016/j.jmatprotec.2005.05.040

Sumantra, Mandal, et al. (2009). Artificial neural network modeling to evaluate and predict the deformation behavior of stainless steel type
AISI 304L during hot torsion. Applied Soft Computing, 9(1), 237244. https://doi.org/10.1016/j.asoc.2008.03.016

Zhang, Z., \& Friedrich, K. (2003). Artificial neural networks applied to polymer composites: a review. Composites Science and technology, 63(14), 2029-2044.

Zhang, Z., Klein, P., \& Friedrich, K. (2002). Dynamic mechanical properties of PTFE based short carbon fibre reinforced composites: experiment and artificial neural network prediction. Composites Science and Technology, 62(7-8). 1001-1009. https://doi.org/10.1016/S0266-3538(02)00036-2

Zhou, C. C., Yin, G. F., Hu, X. B., Zhou, Chang-Chun, Guo-Fu, Yin, \& Xiao-Bing, Hu. (2009). Multi-objective optimization of material selection for sustainable products: artificial neural networks and genetic algorithm approach. Materials \& Design, 30(4), 1209-1215. https://doi.org/10.1016/j.matdes.2008.06.006

Национальный технический университет "Харьковский политехнический институт", г. Харьков, Украина

\section{МОДЕЛИРОВАНИЕ МЕХАНИЧЕСКОГО ПОВЕДЕНИЯ ЭЛАСТОМЕРНЫХ МАТЕРИАЛОВ С ПОМОЩЬЮ ИСКУССТВЕННЫХ НЕЙРОННЫХ СЕТЕЙ}

В XXI в. нейронные сети часто используются в разных сферах, в том числе в компьютерном моделировании и механике. Такая популярность из-за того, что они дают высокую точность, быстро работают и имеют очень обширный спектр настроек. Целью работы является создание программного продукта с использованием элементов искусственного интеллекта для интерполяции и аппроксимации экспериментальных данных. Программное обеспечение должно корректно работать и давать результаты с минимальной ошибкой. Инструментом для решения задачи были использованы элементы искусственного интеллекта, а точнее нейронные сети прямого распространения. Построена нейронная сеть прямого распространения. Она обучалась учителем (учитель с использованием метода обратного распространения ошибки) на основе обучающей выборки предварительно проведенного эксперимента. Для тестирования было построено несколько сетей разной структуры, которые на вход получали одинаковый набор данных, который не использовался при обучении, но был известен из эксперимента. Таким образом, была найдена ошибка сети по количеству выделенной энергии и среднеквадратическому отклонению. Подробно описаны тип сети и ее топология. Метод обучения и подготовка обучающей выборки также описаны математически. В результате проведенной роботы построено и протестировано программное обеспечение с использованием искусственной нейронной сети и определена ошибка ее работы.

Ключевые слова: искусственная нейронная сеть; компьютерное моделирование; искусственный интеллект; аппроксимация; интерполяция; программное обеспечение.

S. V. Pogrebnyak, O. O. Vodka

National Technical University "Kharkiv Polytechnic Institute", Kharkiv, Ukraine

\section{MODELING OF MECHANICAL BEHAVIOR OF ELASTOMERIC MATERIALS USING AN ARTIFICIAL NEURAL NETWORK}

In the 21 st century neural networks are widely used in various fields, including computer simulation and mechanics. This popularity is caused by the fact that they give high precision, work fast and have a very wide range of settings. The use of artificial neural networks is one of the most popular alternative methods of constructing a deformation curve. With the right choice of the network parameters you can achieve good results not only in the approximation of data but also in the interpolation. The purpose of the work is creating a software product using elements of artificial intelligence for interpolation and approximation of experimental data. The software should work correctly and yield results with minimal error. The solution tool of the problem was use of elements of artificial intelligence but rather neural networks of direct distribution. The neural network of direct distribution was built and trained in this work. It was trained by a teacher (a teacher using the method of reverse error propagation) based on a learning sample of a pre-experiment. For each of the learning types the similarities are being found. During the training with the teacher there is a correction of weight coefficients. After each iteration, the teacher compares the network response and the response that should have been received and adjusts it in order to reduce the difference between the response of the network and the response of the experiment (this mistake is called the learning error). Several networks of different structures were built for testing which received the same dataset that was not used during the training but was known from the experiment. Thus, the network error was found in the amount of allocated energy and the mean square deviation. The article describes in detail the type of network and its topology. The method of teaching and preparing a teaching sample is also described mathematically. As a result of the work, the software was constructed and tested using the artificial neural network and its error was determined. As a result of the experiments it was obtained that the network gives a fairly good results in a well-trained network. This network allows in the future interpolating intermediate results with high accuracy and easily receiving the amount of radiated energy. Neural networks are often used to predict the properties of materials (including composite) from a data set.

Keywords: artificial neural network; computer modeling; artificial intelligence; approximation; interpolation; software. 